\title{
Design and Modeling of a Linear Speed Sensor with a Flat Type Structure and Air Coils
}

\author{
Mehran Mirzaei, Pavel Ripka, Andrey Chirtsov, Jan Vyhnanek, and Vaclav Grim \\ Faculty of Electrical Engineering, Czech Technical University, Prague 16627, Czech Republic \\ (e-mail: mirzameh@fel.cvut.cz)
}

\begin{abstract}
This paper presents the design and modeling of a linear eddy current speed sensor with a flat type structure and an air coil configuration. The theory of the eddy current speed sensor is based on utilizing the speed component of the induced currents in a solid moving conductor under stationary or alternating source fields. The stationary part comprises one rectangular excitation coil and two antiserially connected rectangular pick-up coils on the left and right sides of the excitation coil in the direction of the trajectory of the moving part. The moving part is considered firstly as a rectangular conductive ferromagnetic solid iron plate, and secondly as a rectangular aluminum plate. A 3D analytical model using Fourier series is developed to analyze the linear speed sensor in Cartesian coordinates. In addition, the 3D numerical finite element method is used for simulations of the linear speed sensor, and the results are compared with the results for analytical methods. The effects of iron permeability on the speed sensor are calculated for a rectangular ferromagnetic solid iron bar or conductor. The experimental results are presented for a linear speed sensor for a rectangular ferromagnetic solid iron plate and also for a rectangular aluminum plate, at variable speeds. The calculation and the experimental results show that the speed sensor outputs differ completely for solid iron conductive plates and for aluminum conductive plates, due to the different electrical conductivities and magnetic permeabilities.
\end{abstract}

Index Terms-Flat type, linear speed sensor, eddy current, aluminum, iron, analytical method and finite element method.

\section{INTRODUCTION}

Speed sensors are needed for rotating and translational

energy converters [1]-[5]. Non-magnetic optical sensors, variable reluctance sensors, eddy current-based sensors and Hall effect magnetic sensors can be developed for speed measurements. Magnetic sensors could have a moving or stationary permanent magnet or coil as the excitation source. The principles of magnetic sensors are based on the magnetic properties of the sensing material, or on a change in the parameters of the magnetic circuit [6]. Magnetic sensors are more reliable and more robust to dust and dirt than nonmagnetic sensors [7]-[8], especially when the position and the speed of moving objects are being measured.

Eddy current-based speed sensors are widely used for various configurations and applications [6] and [9]-[15]. For example, the Faraday generator, the homopolar generator and magnetic flowmeters [6] and [15] are the earliest utilization of the speed effect in moving conductive objects subjected to magnetic fields. Perpendicular and non-perpendicular pick-up coils for eddy current speed sensors are analyzed using the Fourier transform in [9]-[11], as is presented later using a ferrite core in [12]. Aluminum moving part is used in [9]-[12], which has relative magnetic permeability equal to 1 . An eddy current speed sensor with an axisymmetric structure was developed and measured at variable speeds with a ferromagnetic iron rod [13]. It has three coils for excitation and pick-up voltage. The eddy current-based speed sensor has a quite simple and cost-effective structure, which is an essential consideration for industrial applications.

Our solution for flat type linear speed measurements is based on a single coil excitation coil with an AC current and two pick-up coils for measurements without using a ferromagnetic yoke. In order to analyze the eddy current speed sensor, a fast and precise 3D analytical method is presented for calculating the coil inductance and the induced voltages in the pick-up coils. This method takes into account the eddy currents in the moving conductive part caused by alternating current and the speed of the moving current part for a flat shape model, using Fourier series. General closed-form equations are also obtained for the output results. A 3D timestepping finite element method (FEM) simulation taking into account the speed of the moving part is also presented for a comparison with analytical calculations. Various relative magnetic permeabilities and conductivities are considered for the solid iron moving part in order to evaluate the effects of the electrical and magnetic parameters on the performance of the eddy current speed sensor. The sensitivity of the eddy current speed sensor versus the gap between coils and moving plate is also evaluated. Flat shape aluminum rectangular plates and solid ferromagnetic iron rectangular plates are both used in the measurements for the moving part, and the experimental 
M. Mirzaei, J. Vyhnanek, A. Chirtsov, V. Grim, P. Ripka: Design and Modeling of a Linear Speed Sensor with a Flat Type Structure and Air Coils, JMMM Vol. 495 (2020) article \#165834,pp 1-10, https://doi.org/10.1016/j.jmmm.2019.165834

results at variable speeds are compared with analytical calculations.

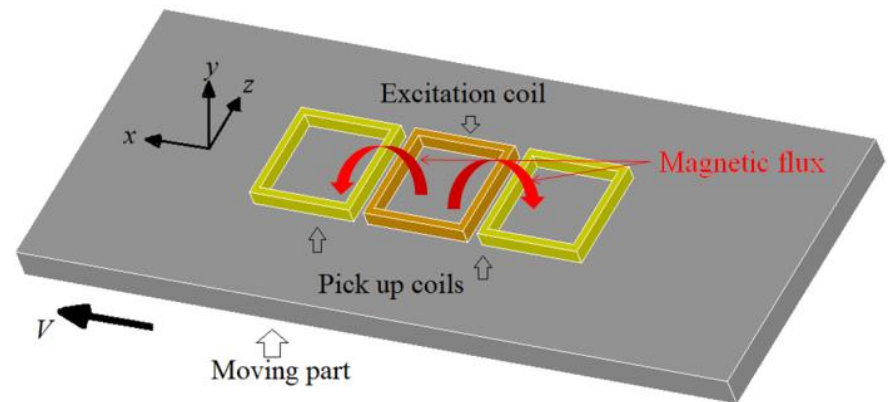

Fig. 1. Flat type eddy current speed sensor
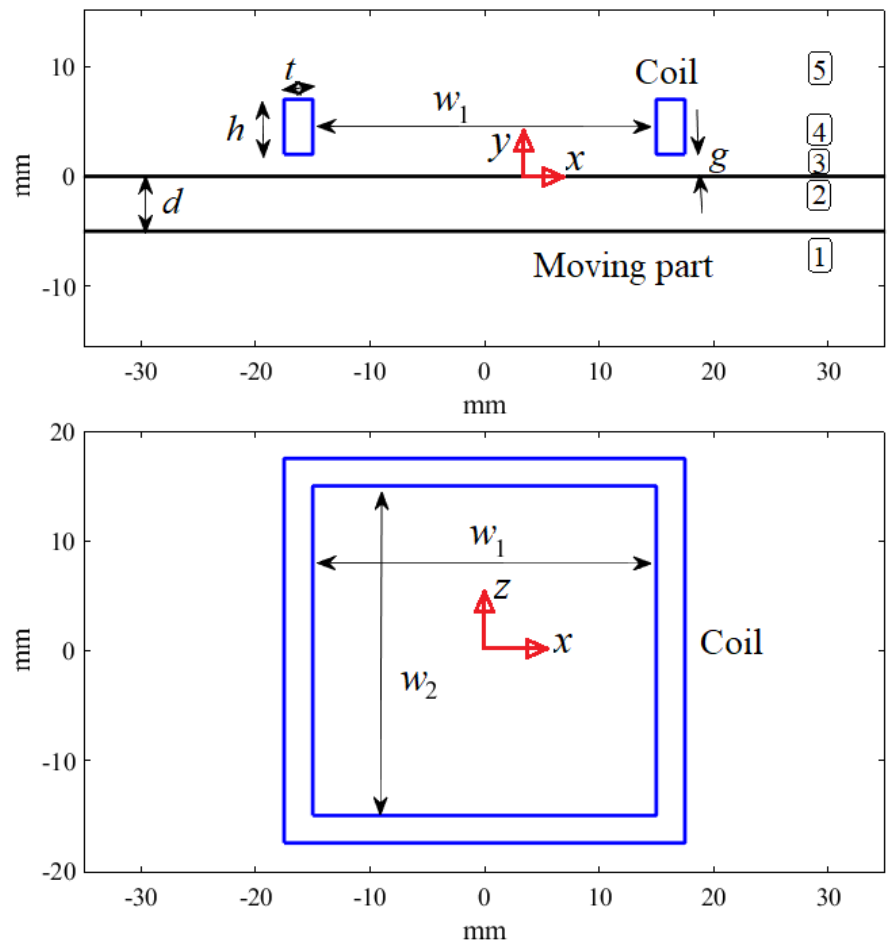

Fig. 2. Computational models - in the $x-y$ plane (above) and in the $x-z$ plane (below)

\section{MODEL AND COIL CONFIGURATIONS}

Fig. 1 shows a 3D model of a flat type eddy current speed sensor coils and solid conductor moving part. The middle coil is the excitation coil, and the coils on the left and right sides are the pick-up coils, which are connected antiserially. The moving part is made of solid iron or of aluminum. Only 1-D movement is considered with speed $V$ in the direction of the $\mathrm{x}$ axis (Fig. 1).

It is obvious that the induced voltage in the pick-up coils in both of these configurations is zero at zero speed, because the net flux linkage is zero in the antiserially connected pick-up coils (Fig. 1).

Fig. 2 and Table I show the parameters and the dimensions of a linear speed sensor. Parameters $d, h, t, g, w_{1}, w_{2}, \sigma_{\mathrm{al}}, \sigma_{\mathrm{i}}$ and $\mu_{\mathrm{ri}}$ are the thickness of the moving part, the coil height, the coil thickness, the gap between the coils and the moving part (the air gap), the inner width of the coils in the $\mathrm{x}$-direction, the inner width of the coils in the z-direction, the electrical conductivity of aluminum, the electrical conductivity of iron, and the relative magnetic permeability of iron, respectively. Regions 1, 2, 3, 4 and 5 in Fig. 2 (above) are the region below the moving part, in the moving part, the air region between the coils and the moving part, in the region of the coils, and the air region above the coils, respectively.

TABLE I

LINEAR SPEED SENSOR PARAMETERS

\begin{tabular}{cc}
\hline \hline Parameters & Values \\
\hline$I$ & $154 \mathrm{~mA}$ \\
$N$ & 100 \\
$d$ & $5 \mathrm{~mm}$ and $10 \mathrm{~mm}$ \\
$h$ & $5.0 \mathrm{~mm}$ \\
$t$ & $2.5 \mathrm{~mm}$ \\
$g$ & $2 \mathrm{~mm}$ \\
$w_{1}$ & $30 \mathrm{~mm}$ \\
$w_{2}$ & $30 \mathrm{~mm}$ \\
$\sigma_{\mathrm{al}}$ & $30.3 \mathrm{MS} / \mathrm{m}$ \\
$\sigma_{\mathrm{i}}$ & $5.24 \mathrm{MS} / \mathrm{m}$ \\
$\mu_{\mathrm{ri}}$ & 100 \\
\hline \hline
\end{tabular}

III. 3D MODELING

\section{A. Analytical}

3D modeling and analysis is required for the proposed eddy current speed sensor, because the air coil configuration is used. 2D analysis is not accurate enough to take the 3D fluxes into account. The general partial differential equations in $3 \mathrm{D}$, using the Maxwell equations, are as follows [16]:

$\nabla \cdot A=0 \rightarrow \frac{\partial A_{x}}{\partial x}+\frac{\partial A_{z}}{\partial z}=0$

$\nabla^{2} A_{x}-\mu \sigma \frac{d A_{x}}{d t}=-\mu J_{s, x}$

$\frac{d A_{x}}{d t}=\frac{\partial A_{x}}{\partial t}+\frac{d x}{d t} \cdot \frac{\partial A_{x}}{\partial x}=\frac{\partial A_{x}}{\partial t}+V \cdot \frac{\partial A_{x}}{\partial x}$

$\frac{\partial^{2} A_{x}}{\partial x^{2}}+\frac{\partial^{2} A_{x}}{\partial y^{2}}+\frac{\partial^{2} A_{x}}{\partial z^{2}}-\mu \sigma\left(\frac{\partial A_{x}}{\partial t}+V \cdot \frac{\partial A_{x}}{\partial x}\right)=-\mu J_{s, x}$

$\nabla^{2} A_{z}-\mu \sigma \frac{d A_{z}}{d t}=-\mu J_{s, z}$

$\frac{d A_{z}}{d t}=\frac{\partial A_{z}}{\partial t}+\frac{d x}{d t} \cdot \frac{\partial A_{z}}{\partial x}=\frac{\partial A_{z}}{\partial t}+V \cdot \frac{\partial A_{z}}{\partial x}$

$\frac{\partial^{2} A_{z}}{\partial x^{2}}+\frac{\partial^{2} A_{z}}{\partial y^{2}}+\frac{\partial^{2} A_{z}}{\partial z^{2}}-\mu \sigma\left(\frac{\partial A_{z}}{\partial t}+V \cdot \frac{\partial A_{z}}{\partial x}\right)=-\mu J_{s, z}$

where $A_{x}$ and $A_{z}$ are the x-axis and z-axis components of the magnetic vector potentials, $\mu$ is relative magnetic permeability, $\sigma$ is electrical conductivity, and $J_{\mathrm{s}, \mathrm{x}}$ and $J_{\mathrm{s}, \mathrm{z}}$ are the $\mathrm{x}$-axis and $z$-axis components of the source current densities in the excitation coil. Only linear magnetic modeling using the initial permeability is considered here, due to the low magnetic fields in the sensor, and nonlinearity and hysteresis effects are neglected. The $y$-component of the magnetic vector potential is considered to be zero, because the excitation coil is 
M. Mirzaei, J. Vyhnanek, A. Chirtsov, V. Grim, P. Ripka: Design and Modeling of a Linear Speed Sensor with a Flat Type Structure and Air Coils, JMMM Vol. 495 (2020) article \#165834,pp 1-10, https://doi.org/10.1016/j.jmmm.2019.165834

parallel to the $x-z$ plane, and the $y$-component of the source current density is therefore zero [16]-[17].

The method of separation of variables (the Fourier method) is used to solve (1) [16]-[17].

It is assumed that the magnetic fields change sinusoidally against time and periodically in the $x$-direction with period length $l$ and in the $z$-direction with period length $L$. The derivations in (1) can therefore be replaced as follows:

$$
A_{z}=X(x) \cdot Y(y) \cdot Z(z) \cdot T(t)
$$

$$
\begin{aligned}
& X(x) \propto \exp \left(-j k_{m} \cdot x\right), k_{m}=m \frac{\pi}{l}, m= \pm 1, \pm 3, \pm 5, \cdots \\
& Z(z) \propto \exp \left(-j k_{n} \cdot z\right), k_{n}=n \frac{\pi}{L}, n= \pm 1, \pm 3, \pm 5, \cdots \\
& T(t) \propto \exp (j \omega \cdot t) \\
& \frac{\partial A_{z}}{\partial t}=j \omega \cdot A_{z} \\
& \omega=2 \pi f \\
& \frac{\partial A_{x, z}}{\partial x}=-j k_{m} \cdot A_{x, z}, \frac{\partial^{2} A_{x, z}}{\partial x^{2}}=-k_{m}^{2} \cdot A_{x, z} \\
& \frac{\partial^{2} A_{x, z}}{\partial z^{2}}=-k_{n}^{2} \cdot A_{x, z}
\end{aligned}
$$

where $f$ is frequency. $m$ and $n$ are harmonic orders.

The solutions of (1) versus $y$ for regions $1\left(A_{\mathrm{z}, 1}\right), 2\left(A_{\mathrm{z}, 2}\right), 3$ $\left(A_{\mathrm{z}, 3}\right), 4\left(A_{\mathrm{z}, 4}\right)$ and $5\left(A_{\mathrm{z}, 5}\right)$ are as follows:

$$
\begin{aligned}
& A_{z, 1}=\sum_{n} \sum_{m}\left(C_{11} \exp \left(\gamma_{1} y\right)+C_{12} \exp \left(\gamma_{1} y\right)\right) \\
& \times \exp \left(j\left(\omega t-k_{m} x-k_{n} z\right)\right) \\
& \gamma_{1}=\gamma,\left(\gamma=\sqrt{k_{m}^{2}+k_{n}^{2}}\right), A_{x, 1}=-\frac{k_{n}}{k_{m}} A_{z, 1} \\
& A_{z, 2}=\sum_{n} \sum_{m}\left(C_{21} \exp \left(\gamma_{2} y\right)+C_{22} \exp \left(\gamma_{2} y\right)\right) \\
& \times \exp \left(j\left(\omega t-k_{m} x-k_{n} z\right)\right) \\
& \gamma_{2}=\sqrt{\gamma^{2}+j \mu_{2} \sigma\left(\omega-k_{m} \cdot V\right)}, \quad A_{x, 2}=-\frac{k_{n}}{k_{m}} A_{z, 2} \\
& A_{z, 3}=\sum_{n} \sum_{m}\left(C_{31} \exp \left(\gamma_{3} y\right)+C_{32} \exp \left(\gamma_{3} y\right)\right) \\
& \times \exp \left(j\left(\omega t-k_{m} x-k_{n} z\right)\right) \\
& \gamma_{3}=\gamma, A_{x, 3}=-\frac{k_{n}}{k_{m}} A_{z, 3} \\
& A_{z, 4}=\sum_{n} \sum_{m}\left(C_{41} \exp \left(\gamma_{4} y\right)+C_{42} \exp \left(\gamma_{4} y\right)+\frac{\mu_{4} J_{m}}{\gamma^{2}}\right) \\
& \times \exp \left(j\left(\omega t-k_{m} x-k_{n} z\right)\right) \\
& \gamma_{4}=\gamma, A_{x, 4}=-\frac{k_{n}}{k_{m}} A_{z, 4} \\
& A_{z, 5}=\sum_{n} \sum_{m}\left(C_{51} \exp \left(\gamma_{5} y\right)+C_{52} \exp \left(\gamma_{5} y\right)\right) \\
& \times \exp \left(j\left(\omega t-k_{m} x-k_{n} z\right)\right) \\
& \gamma_{5}=\gamma, A_{x, 5}=-\frac{k_{n}}{k_{m}} A_{z, 5}
\end{aligned}
$$

where $C_{11}, C_{12}, C_{21}, C_{22}, C_{31}, C_{32}, C_{41}, C_{42}, C_{51}$ and $C_{52}$ are constants, and they are calculated by the boundary conditions between regions 1 to 5 in (5).

$$
\begin{aligned}
& A_{z, 1}(y=-\infty)=0 \\
& A_{z, 1}(y=-d)=A_{z, 2}(y=-d) \\
& H_{x, 1}(y=-d)=H_{x, 2}(y=-d) \\
& A_{z, 2}(y=0)=A_{z, 3}(y=0) \\
& H_{x, 2}(y=0)=H_{x, 3}(y=0) \\
& A_{z, 3}(y=g)=A_{z, 4}(y=g) \\
& H_{x, 3}(y=g)=H_{x, 4}(y=g) \\
& A_{z, 4}(y=g+h)=A_{z, 5}(y=g+h) \\
& H_{x, 4}(y=g+h)=H_{x, 5}(y=g+h) \\
& A_{z, 5}(y=\infty)=0
\end{aligned}
$$

where $H_{\mathrm{x}}$ is the $x$-component of the magnetic field strength. Parameter $J_{\mathrm{m}}$ in (4) for coil excitation is obtained as follows: 


$$
\begin{aligned}
& J_{\mathrm{m}}=4 \frac{j}{n \pi l} C_{J} \cdot J_{\mathrm{s}} \\
& C_{J}=\frac{1}{k_{m}+k_{n}} C_{J, 1} \cdot C_{J, 2}-\frac{1}{k_{m}-k_{n}} C_{J, 3} \cdot C_{J, 4} \\
& C_{J, 1}=\cos \left(k_{m} \frac{w_{1}+t}{2}+k_{n} \frac{w_{2}+t}{2}\right) \\
& C_{J, 2}=\sin \left(k_{m} \frac{t}{2}+k_{n} \frac{t}{2}\right) \\
& C_{J, 3}=\cos \left(k_{m} \frac{w_{1}+t}{2}-k_{n} \frac{w_{2}+t}{2}\right) \\
& C_{J, 4}=\sin \left(k_{m} \frac{t}{2}-k_{n} \frac{t}{2}\right) \\
& J_{\mathrm{s}}=\frac{N \cdot I}{h \cdot t}
\end{aligned}
$$

where $N$ and $I$ are the number of turns per coil and the current amplitude (Table I), respectively.

In this paper, it is considered that the excitation coil and the pick-up coils have same dimensions. The mutually-induced voltage, $U_{\mathrm{M}}$, and the mutual inductance, $L_{\mathrm{M}}$, can be calculated as follows [16], [18]-[19]:

$$
L_{\mathrm{M}}=\frac{\Psi_{M}}{I}=\frac{N \int\left(\int A_{4} \cdot d l\right) d s}{I \cdot h \cdot t}
$$

where $\Psi_{\mathrm{M}}$ is the total average mutual flux linkage over the volume of the coils. Line integration of $A_{4}$ (magnetic vector potential in the coil region 4 in (4) is applied to each coil in the current flow direction, as in an excitation coil. The surface integration in (7) is for the coil cross-section area, which is averaged over the coil cross-section area, $h \cdot t$.

The differential voltage between the left and right side pickup coils (Fig. 1) is presented in (8) and (9). The polarity of the differential voltage changes with the changes in speed direction, according to (8) and (9).

$U_{d}=U_{\mathrm{M}, l}-U_{\mathrm{M}, r}=j \omega \cdot\left(L_{\mathrm{M}, r}-L_{\mathrm{M}, l}\right) \cdot I$

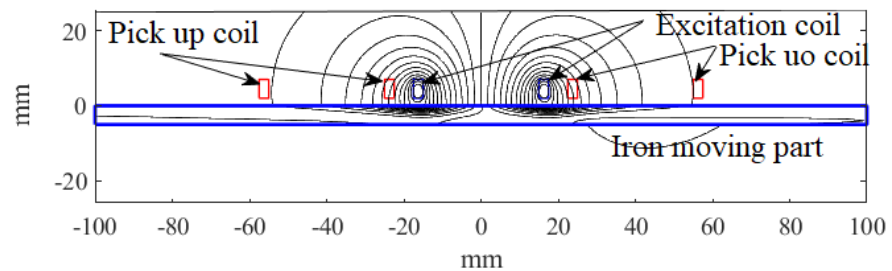

Fig. 3. Magnetic flux distribution in the $x-y$ plane for the iron moving part at $100 \mathrm{~Hz}$ and $2 \mathrm{~m} / \mathrm{s}$

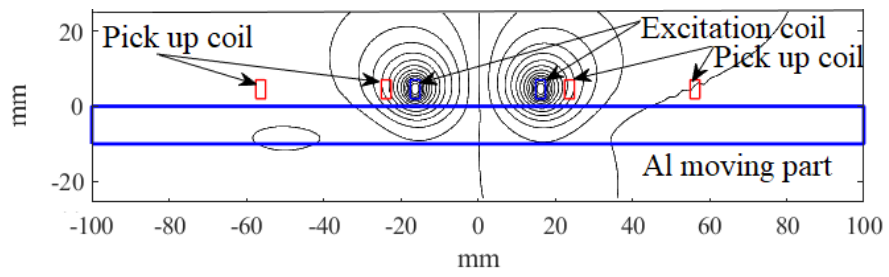

Fig. 4. Magnetic flux distribution in the $\mathrm{x}-\mathrm{y}$ plane for the aluminum moving part at $100 \mathrm{~Hz}$ and $2 \mathrm{~m} / \mathrm{s}$

$$
\begin{aligned}
& U_{d}=U_{\mathrm{M}, l}-U_{\mathrm{M}, r}=\frac{2 \omega N \cdot L \cdot l}{h \cdot t} \sum_{n} \sum_{m \cdot}\left(C_{U} C_{J} \sin \left(k_{m} w_{3}\right)\right) \\
& C_{U}=\frac{4 j}{n \pi l}\left(1+\left(\frac{k_{n}}{k_{m}}\right)^{2}\right) \cdot\left(C_{U, 1}+C_{U, 2}+C_{U, 3}\right) \\
& C_{U, 1}=\frac{C_{41}}{\gamma_{4}} \cdot\left(\exp \left(\gamma_{4} \cdot(h+g)\right)-\exp \left(\gamma_{4} \cdot g\right)\right) \\
& C_{U, 2}=-\frac{C_{42}}{\gamma_{4}} \cdot\left(\exp \left(-\gamma_{4} \cdot(h+g)\right)-\exp \left(-\gamma_{4} \cdot g\right)\right) \\
& C_{U, 3}=\frac{\mu_{0} \cdot J_{m}}{\gamma_{4}^{2}} \cdot h
\end{aligned}
$$

where $w_{3}$ is the distance between the pick-up coils and the centers of the excitation coil.

The magnetic flux density distribution and the eddy current distribution for iron and aluminum moving parts at $100 \mathrm{~Hz}$ and $2 \mathrm{~m} / \mathrm{s}$ are shown in Fig. 3 - Fig. 6. The iron moving part is $5 \mathrm{~mm}$ in thickness, and the aluminum moving part is $10 \mathrm{~mm}$ in thickness (Table I). The skin depths are $2.2 \mathrm{~mm}$ for the iron moving part, and $9.1 \mathrm{~mm}$ and for the aluminum moving part, at $100 \mathrm{~Hz}$. The speed effect on the differential induced voltage could be higher for an aluminum moving part than for an iron moving part, as the skin depth is greater in aluminum (Fig. 4). The deformation and the extension of the induced eddy currents in the iron moving part due to the speed effect is larger, because of the higher relative permeability.

Fig. 7 and Fig. 8 show differential voltages and flux linkages versus frequency for iron and aluminum moving parts. The differential voltage for the iron moving part increases with frequency, with the exception of some fluctuation between $75 \mathrm{~Hz}$ and $125 \mathrm{~Hz}$ (Fig. 7). The maximum differential voltage value for the aluminum moving part is located at $75 \mathrm{~Hz}$ in Fig. 8, and the differential voltage decreases continuously at higher frequencies for the aluminum moving part.

The flux linkages decrease at higher frequencies, which shows that lower frequencies or DC are best for obtaining maximum flux linkage or magnetic flux density, and the flux linkages are more sensitive to speed at lower frequencies. 
M. Mirzaei, J. Vyhnanek, A. Chirtsov, V. Grim, P. Ripka: Design and Modeling of a Linear Speed Sensor with a Flat Type Structure and Air Coils, JMMM Vol. 495 (2020) article \#165834,pp 1-10, https://doi.org/10.1016/j.jmmm.2019.165834

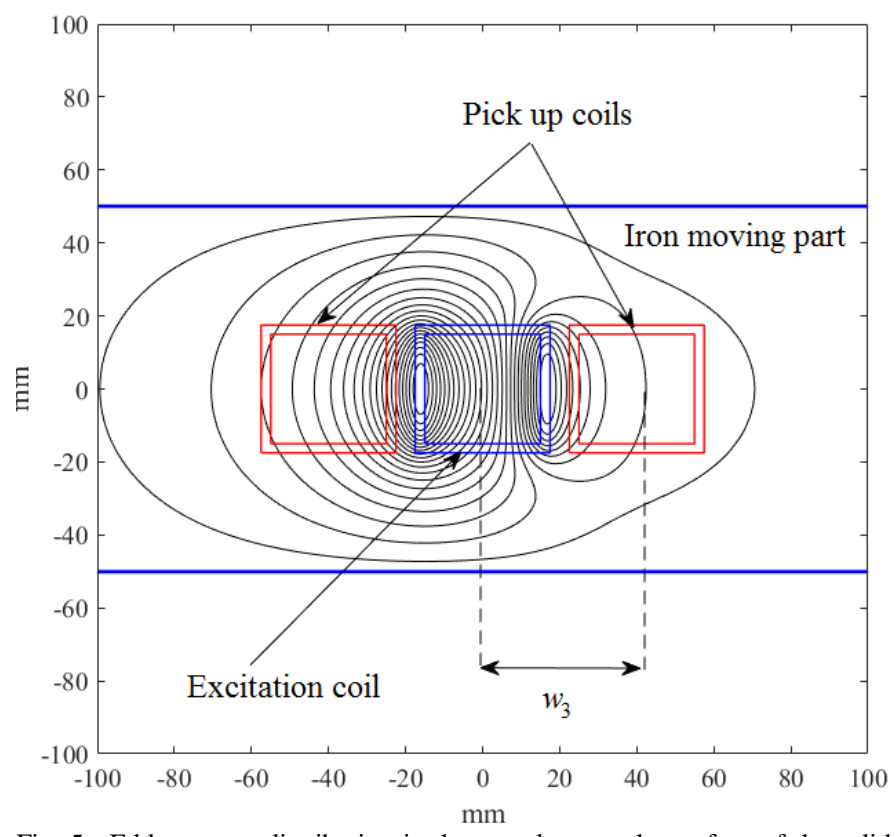

Fig. 5. Eddy current distribution in the $x-z$ plane on the surface of the solid iron moving part at $100 \mathrm{~Hz}$ and $2 \mathrm{~m} / \mathrm{s}$

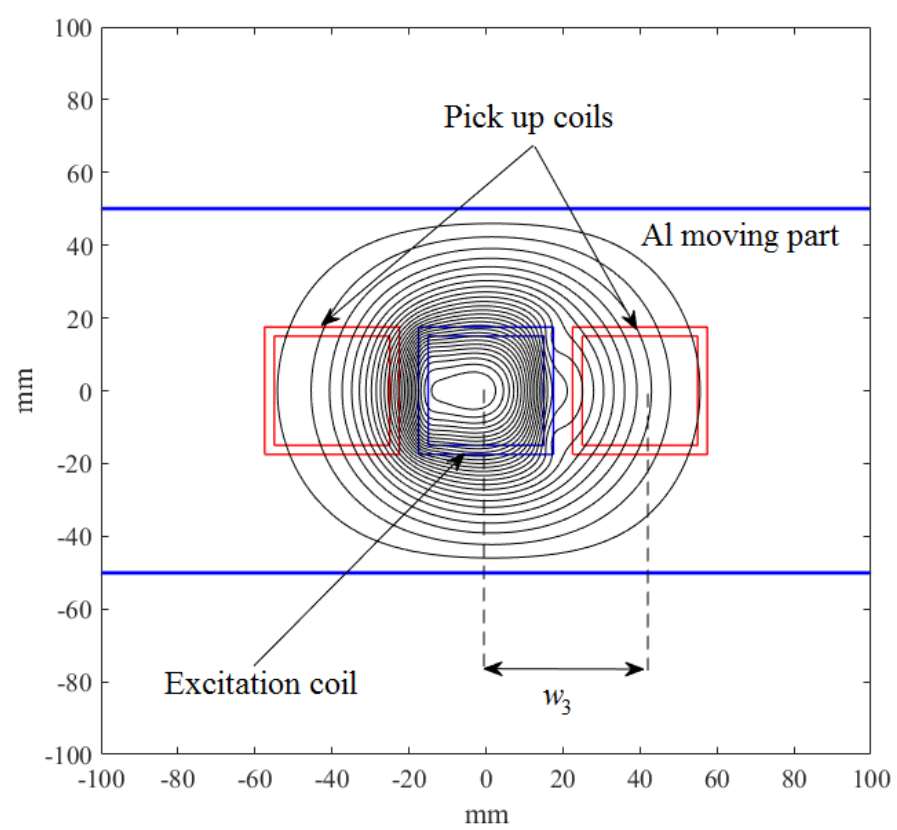

Fig. 6. Eddy current distribution in the $\mathrm{x}-\mathrm{z}$ plane on the surface of the aluminum moving part at $100 \mathrm{~Hz}$ and $2 \mathrm{~m} / \mathrm{s}$

The differential voltages and flux linkages versus the gap between the coils and the moving part are shown in Fig. 9. The differential voltage and the flux linkage decreases monotonically in the case of the aluminum moving part. The differential voltages and the flux linkages for the iron moving part have maximum values for a $3.5 \mathrm{~mm}$ gap. This is due to the high permeability of the iron moving part. The differential voltage and the flux linkage are higher for an aluminum moving part than for an iron moving part for different gaps and frequencies, see in Fig. 7 - Fig. 9.

The differential voltage for a non-magnetic moving part (for example in this paper, aluminum) versus conductivity is shown in Fig. 10. The maximum value is at $22.0 \mathrm{MS} / \mathrm{m}$.

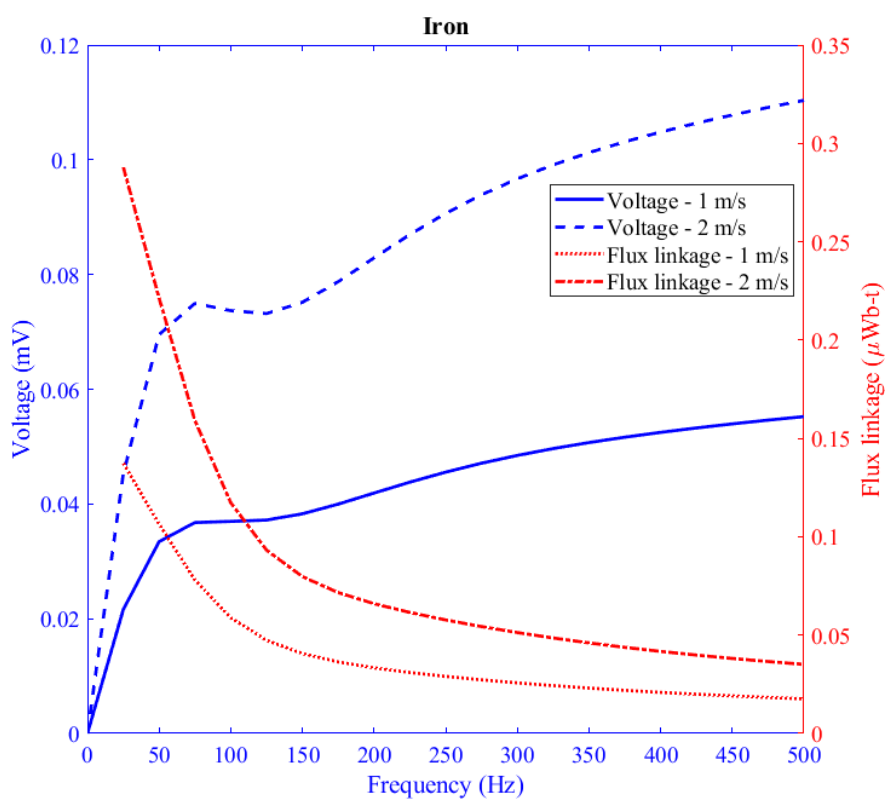

Fig. 7. Amplitude of differential induced voltage and flux linkage versus frequency for the iron moving part - airgap, $g=2 \mathrm{~mm}\left(\mu_{\mathrm{ri}}=100\right)$

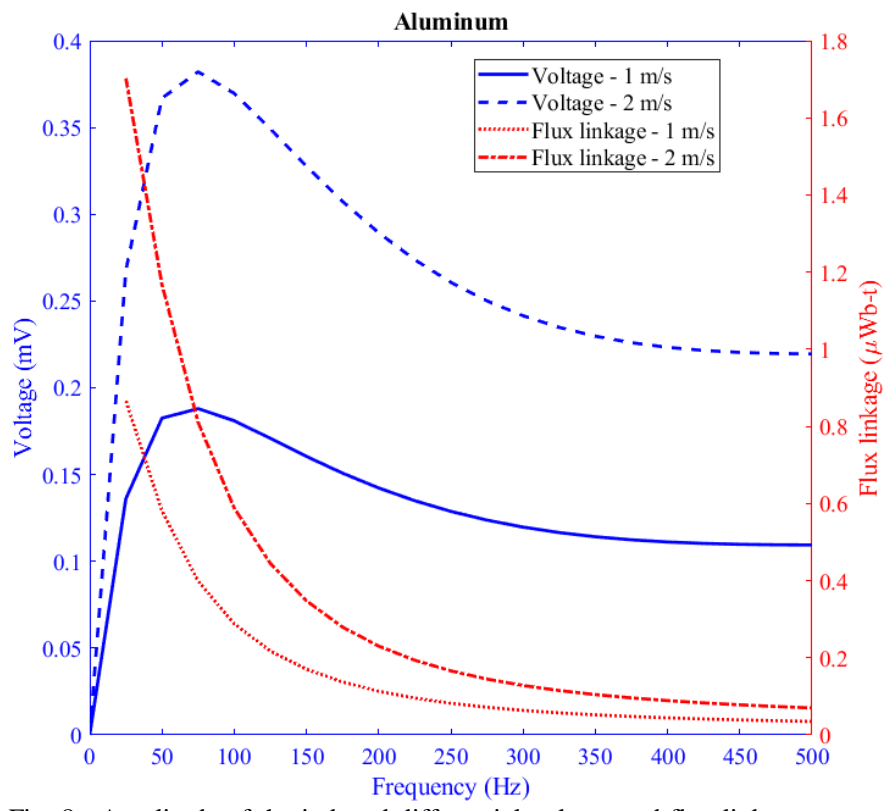

Fig. 8. Amplitude of the induced differential voltage and flux linkage versus frequency for the aluminum moving part - airgap, $g=2 \mathrm{~mm}$

The differential voltage for a magnetic moving part versus conductivity and relative magnetic permeability is presented as a 3D plot in Fig. 11. The relative magnetic permeability varies between 50 and 150, which is an acceptable range for low magnetic fields. Nonlinearity is neglected in the simulations, and constant magnetic permeability is used in the simulations as the magnetic field in the eddy current speed sensor is small. The assumed range of conductivity is between $4 \mathrm{MS} / \mathrm{m}$ and $6 \mathrm{MS} / \mathrm{m}$, which is an expected range for construction steels and irons. The maximum and minimum differential voltage values for iron moving parts are located at 
M. Mirzaei, J. Vyhnanek, A. Chirtsov, V. Grim, P. Ripka: Design and Modeling of a Linear Speed Sensor with a Flat Type Structure and Air Coils, JMMM Vol. 495 (2020) article \#165834,pp 1-10, https://doi.org/10.1016/j.jmmm.2019.165834

conductivity $=6 \mathrm{MS} / \mathrm{m}$, relative magnetic permeability $=50$ and conductivity $=4 \mathrm{MS} / \mathrm{m}$, relative magnetic permeability = 150 , respectively. The sensitivity of the eddy current speed sensor to variations in magnetic permeability is much higher. The sensitivity for an aluminum moving part to variations in conductivity are much lower than for an iron moving part within the same range of conductivity variations (Fig. 10).

The sensitivity of an eddy current speed sensor to the thickness of the moving parts is dependent on the material of the moving part and on the excitation frequency (Fig. 12), because of the skin effects and the flux penetration depth in the conductive moving parts. The maximum values of the differential voltages for iron moving parts are located at a thickness of $4 \mathrm{~mm}$ for $100 \mathrm{~Hz}$ and at a thickness of $2 \mathrm{~mm}$ for $200 \mathrm{~Hz}$. Thicknesses of $6 \mathrm{~mm}$ and $3 \mathrm{~mm}$ are the positions of the maximum values of the differential voltages for an aluminum moving part at $100 \mathrm{~Hz}$ and $200 \mathrm{~Hz}$, respectively.

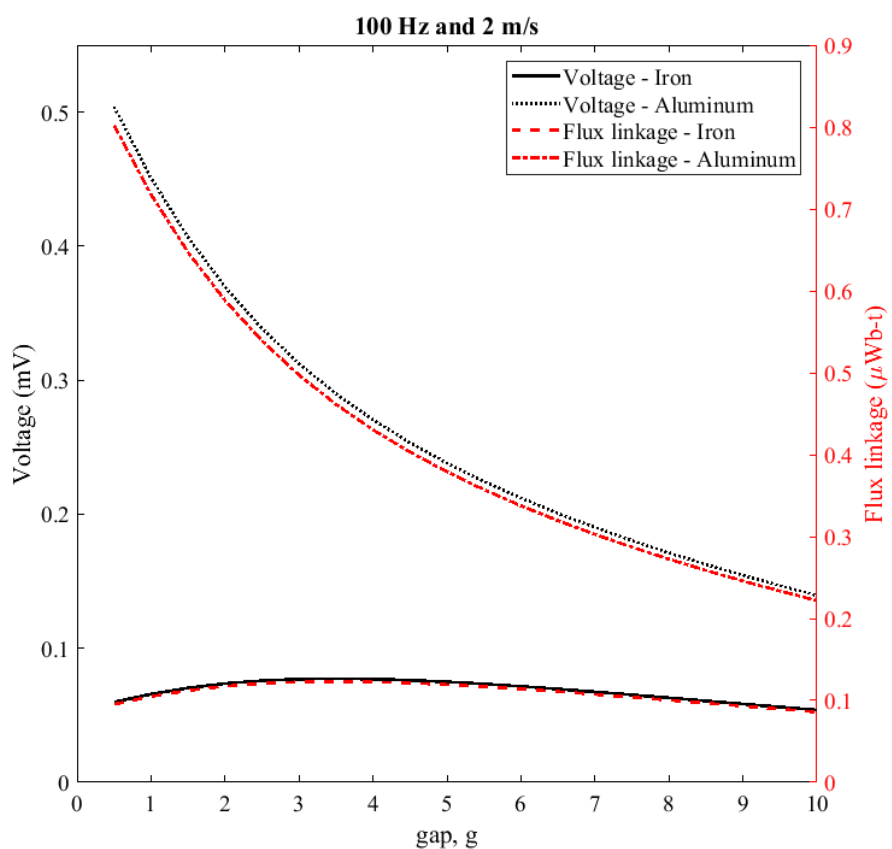

Fig. 9. Amplitude of the induced differential voltage and flux linkage versus gap, g $\left(\mu_{\mathrm{ri}}=100\right)$

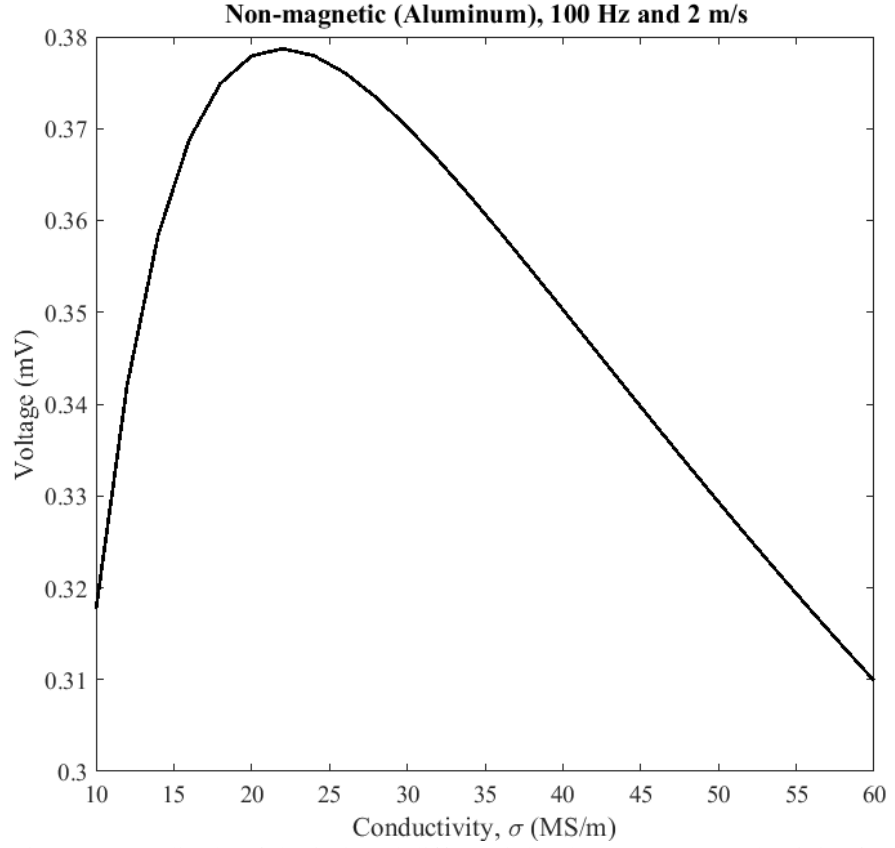

Fig. 10. Amplitude of the induced differential voltage versus conductivity for a nonmagnetic moving part, e.g. aluminum

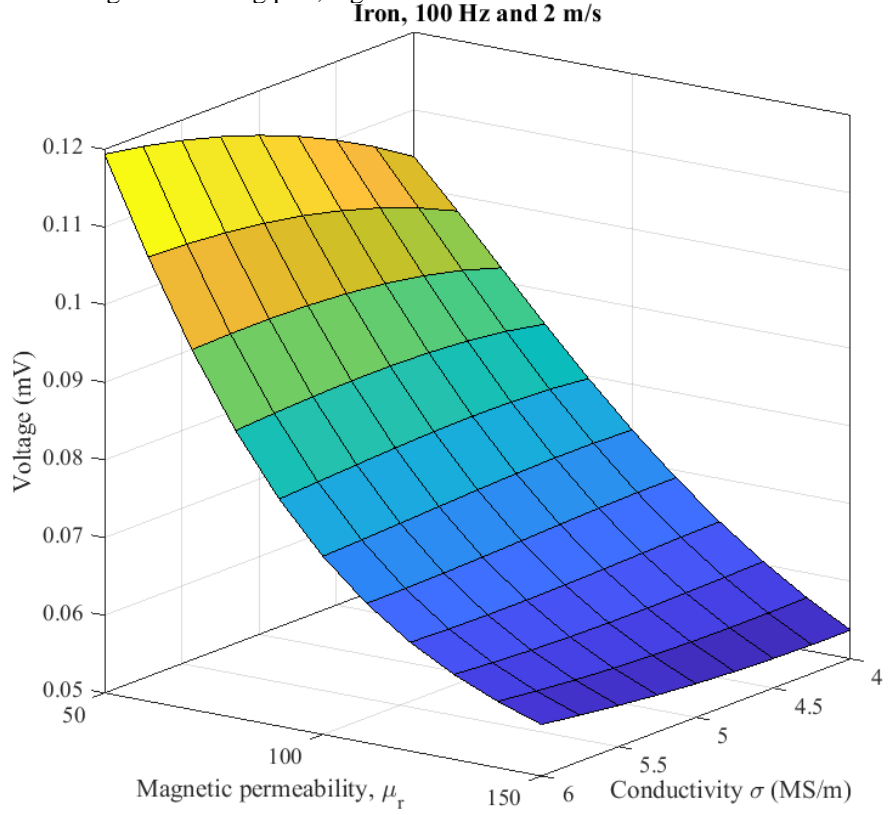

Fig. 11. Amplitude of the induced differential voltage versus conductivity and magnetic relative permeability for a magnetic moving part 
M. Mirzaei, J. Vyhnanek, A. Chirtsov, V. Grim, P. Ripka: Design and Modeling of a Linear Speed Sensor with a Flat Type Structure and Air Coils, JMMM Vol. 495 (2020) article \#165834,pp 1-10, https://doi.org/10.1016/j.jmmm.2019.165834

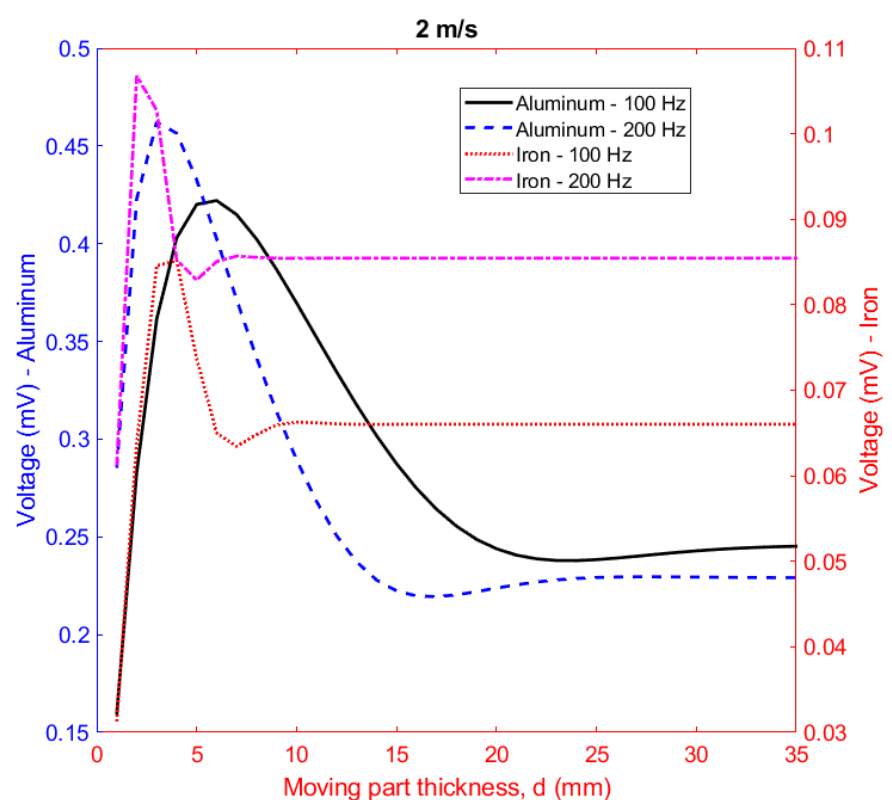

Fig. 12. Amplitude of the induced differential voltage versus moving part thickness - airgap, $g=2 \mathrm{~mm}\left(\mu_{\mathrm{ri}}=100\right)$

Excellent linearity characteristics of a flat type eddy current speed sensor up to $2 \mathrm{~m} / \mathrm{s}$ is shown in Fig. 13. The linear function equations between the differential voltage, $U_{\mathrm{d}}$, and the moving part speed, $V$, are shown as follows:

$U_{d}=K \cdot V$

$V=K^{\prime} \cdot U_{d}, K^{\prime}=K^{-1}$

Constant $\mathrm{K}$ is calculated in Fig. 13. An eddy current speed sensor with an iron moving part has greater sensitivity at $1000 \mathrm{~Hz}$ than at $100 \mathrm{~Hz}$. However, it is not recommended to operate the sensor at very high frequencies due to the smaller skin depth and the greater sensitivity to the surface of an iron moving part, because iron and steel surfaces are affected by corrosion.

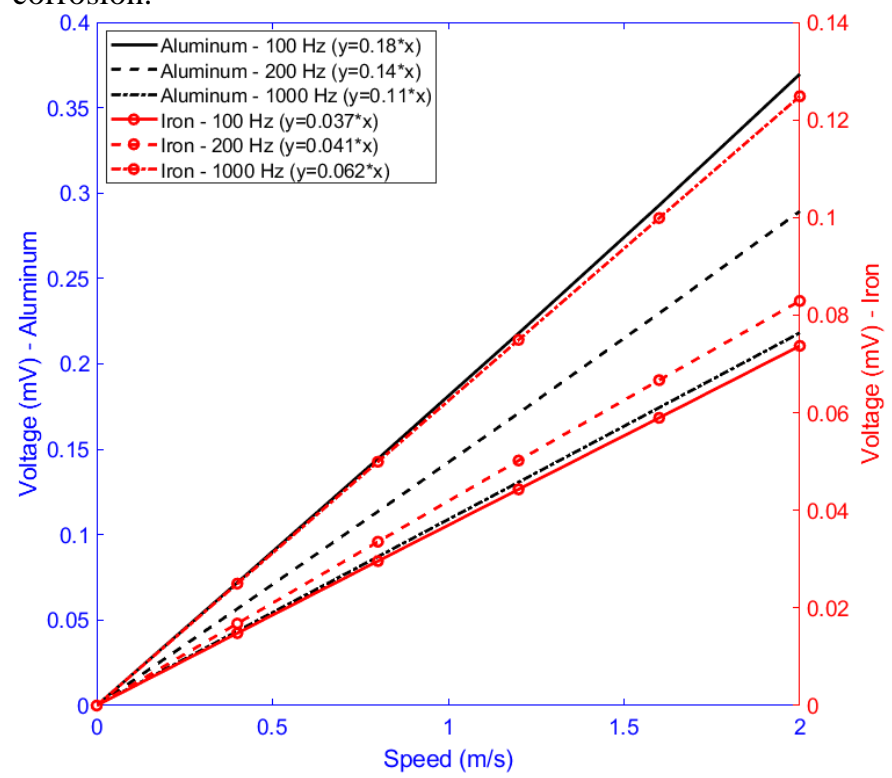

Fig. 13. Amplitude of induced differential voltage versus moving part thickness - airgap, $g=2 \mathrm{~mm}\left(\mu_{\mathrm{ri}}=100\right)$

\section{B. FEM}

Time-stepping 3D FEM is used to model a flat type eddy current speed sensor, taking into account the speed of the moving part. Fig. 14 and Fig. 15 show the eddy current distributions in the iron and aluminum moving parts. The eddy currents are weaker in the iron moving part, and they are located clozer to the surface than in the case of the aluminum moving part. Only one half of the FEM model is analyzed, as the model is symmetric to the $\mathrm{X}-\mathrm{Y}$ plane. A comparison between 3D FEM and the 3D analytical calculations shows that the 3D analytical calculations, which is much faster than 3D FEM, are highly accurate (Table II - Table VI). The difference between 3D FEM and the 3D analytical calculations can be reduced by using a finer mesh and a larger number of mesh elements and a smaller time step for the simulations. However, this significantly increases the 3D FEM simulation time. The relative magnetic permeability of iron is considered to be equal to 100 in the simulations.

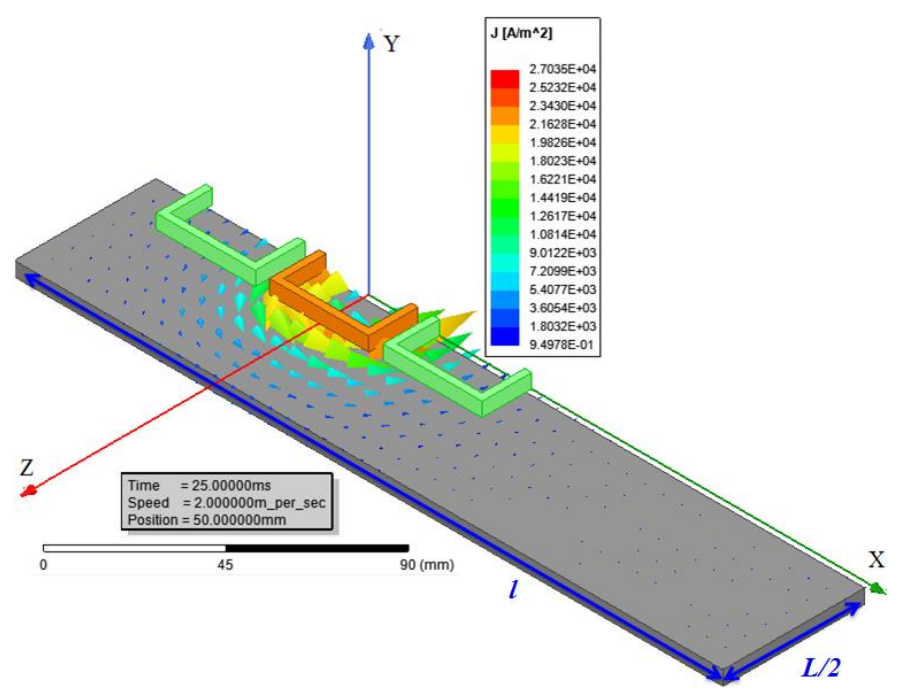

Fig. 14. Eddy current distribution in the $x-z$ plane on the surface of a solid iron moving part at $100 \mathrm{~Hz}$ and $2 \mathrm{~m} / \mathrm{s}\left(\mu_{\mathrm{ri}}=100\right)$

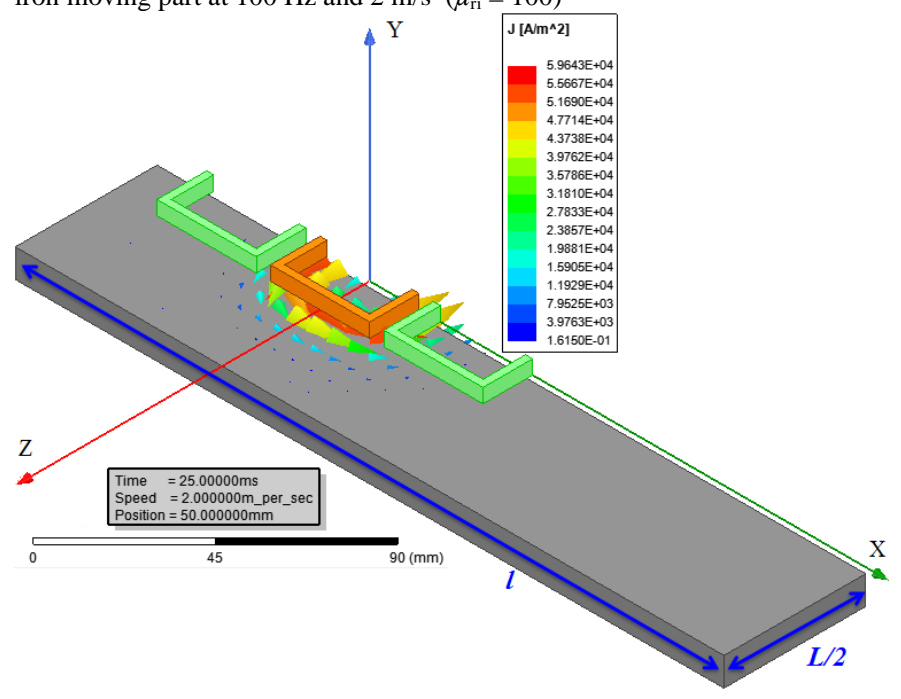


M. Mirzaei, J. Vyhnanek, A. Chirtsov, V. Grim, P. Ripka: Design and Modeling of a Linear Speed Sensor with a Flat Type Structure and Air Coils, JMMM Vol. 495 (2020) article \#165834,pp 1-10, https://doi.org/10.1016/j.jmmm.2019.165834

Fig. 15. Eddy current distribution in the $\mathrm{x}-\mathrm{z}$ plane on the surface of an aluminum moving part at $100 \mathrm{~Hz}$ and $2 \mathrm{~m} / \mathrm{s}$

TABLE II

COMPARISON BETWEEN ANALYTICAL AND 3D FEM AT DIFFERENT SPEEDS DifFERENTIAL VOLTAGE (AMPLITUDE)

\begin{tabular}{cc} 
& DIFFERENTIAL VOLTAGE (AMPLITUDE) \\
\hline \hline$g=2 \mathrm{~mm}$ & Iron $(d=5 \mathrm{~mm})$ \\
$f=100 \mathrm{~Hz}$ & Analytical $/$ FEM \\
\hline$V=0.5 \mathrm{~m} / \mathrm{s}$ & $0.019 / 0.017 \mathrm{mV}$ \\
$V=1.0 \mathrm{~m} / \mathrm{s}$ & $0.037 / 0.034 \mathrm{mV}$ \\
$V=2.0 \mathrm{~m} / \mathrm{s}$ & $0.074 / 0.069 \mathrm{mV}$ \\
\hline
\end{tabular}

TABLE III

COMPARISON BETWEEN ANALYTICAL AND 3D FEM AT HIGHER FREQUENCY DIFFERENTIAL VOLTAGE (AMPLITUDE)

\begin{tabular}{ccc}
\hline \hline$g=2 \mathrm{~mm}$ & Iron $(d=5 \mathrm{~mm})$ & Aluminum $(d=10 \mathrm{~mm})$ \\
$V=2.0 \mathrm{~m} / \mathrm{s}$ & Analytical $/$ FEM & Analytical $/$ FEM \\
\hline$f=200 \mathrm{~Hz}$ & $0.083 / 0.078 \mathrm{mV}$ & $0.289 / 0.263 \mathrm{mV}$ \\
\hline \hline
\end{tabular}

TABLE IV

COMPARISON BETWEEN ANALYTICAL AND 3D FEM FOR HIGHER GAP DIFFERENTIAL VOLTAGE (AMPLITUDE)

\begin{tabular}{ccc} 
& \multicolumn{2}{c}{ DIFFERENTIAL VOLTAGE (AMPLITUDE) } \\
\hline \hline$V=2.0 \mathrm{~m} / \mathrm{s}$ & Iron $(d=5 \mathrm{~mm})$ & Aluminum $(d=10 \mathrm{~mm})$ \\
$f=100 \mathrm{~Hz}$ & Analytical $/$ FEM & Analytical $/$ FEM \\
\hline$g=4 \mathrm{~mm}$ & $0.077 / 0.075 \mathrm{mV}$ & $0.27 / 0.247 \mathrm{mV}$ \\
\hline \hline
\end{tabular}

TABLE V

COMPARISON BETWEEN ANALYTICAL AND 3D FEM FOR DIFFERENT MOVING PART THICKNESS - DIFFERENTIAL VOLTAGE (AMPLITUDE)

\begin{tabular}{ccc}
\hline \hline$g=2 \mathrm{~mm}$ & Iron & Aluminum \\
$f=100 \mathrm{~Hz}$ & Analytical / FEM & Analytical / FEM \\
$V=2.0 \mathrm{~m} / \mathrm{s}$ & - & $0.42 / 0.376 \mathrm{mV}$ \\
$\mathrm{d}=5 \mathrm{~mm}$ & $0.066 / 0.064 \mathrm{mV}$ & - \\
$\mathrm{d}=10 \mathrm{~mm}$ & & \\
\hline \hline
\end{tabular}

Parameters $l$ and $L$ in Fig. 14 and Fig. 15 correspond to the parameters for the calculations, which are mentioned in (3). These parameters are used in the analytical calculations. Parameter $l$ is selected equal to $250 \mathrm{~mm}$, and parameter $L$ is $100 \mathrm{~mm}$, which is similar to the width of the iron and aluminum plates. The maximum values for harmonic orders $m$ and $n$ are selected to be 200 and 100, respectively. These values are a compromise between accuracy and simulation time for the analytical method.

TABLE VI

COMPARISON BETWEEN ANALYTICAL AND 3D FEM FOR DIFFERENT MATERIAL DATA - DIFFERENTIAL VOLTAGE (AMPLITUDE)

\begin{tabular}{ccc}
\hline \hline$g=2 \mathrm{~mm}$ & Iron $(d=5 \mathrm{~mm})$ & Aluminum $(d=10 \mathrm{~mm})$ \\
$f=100 \mathrm{~Hz}$ & Analytical $/$ FEM & Analytical $/$ FEM \\
$V=2.0 \mathrm{~m} / \mathrm{s}$ & - & $0.314 / 0.286 \mathrm{mV}$ \\
\hline$\sigma_{\mathrm{al}}=58 \mathrm{MS} / \mathrm{m}$ & - & $0.379 / 0.342 \mathrm{mV}$ \\
$\sigma_{\mathrm{al}}=22 \mathrm{MS} / \mathrm{m}$ & $0.054 / 0.051 \mathrm{mV}$ & - \\
$\begin{array}{c}\sigma_{\mathrm{i}}=4.0 \mathrm{MS} / \mathrm{m} \\
\left(\mu_{\mathrm{r}}=150\right)\end{array}$ & - \\
$\begin{array}{c}\sigma_{\mathrm{i}}=6.0 \mathrm{MS} / \mathrm{m} \\
\left(\mu_{\mathrm{ri}}=50\right)\end{array}$ & $0.119 / 0.108 \mathrm{mV}$ & \\
\hline \hline
\end{tabular}

\section{EXPERIMENTS}

Fig. 16 shows the experiment set-up elements with the coils and with iron and aluminum moving parts. The high accuracy of the analytical method for calculating the mutual induced voltage in one of the pick-up coils using (12) is shown in Table VII, in comparison with measurements at zero speed of the moving part. Table VIII also presents a comparison calculations using (13) and (14) and the Alumixperifonthtmm)alues for the self- inductances of the excitation Analytical EEM $0.090 j 0.080 \mathrm{mV}$
$0.1891 / 8 \mathrm{t} 189 \mathrm{~m}$ method.

$0.370 / 0.333 \mathrm{mV}$

$$
\begin{aligned}
& \frac{j \omega N \cdot L \cdot l}{h \cdot t} \sum_{n} \sum_{m .}\left(C_{U} C_{J} \exp \left(j k_{m} w_{3}\right)\right)= \\
& \frac{j \omega N \cdot L \cdot l}{h \cdot t} \sum_{n} \sum_{m .}\left(C_{U} C_{J} \exp \left(-j k_{m} w_{3}\right)\right) \\
& L_{\mathrm{S}}=\frac{\Psi_{S}}{I}=\frac{N \int\left(\int A_{4} \cdot d l\right) d s}{I \cdot h \cdot t} \\
& L_{\mathrm{S}}=\frac{N \cdot L \cdot l}{h \cdot t \cdot I} \sum_{n} \sum_{m .}\left(C_{U} C_{J}\right)
\end{aligned}
$$

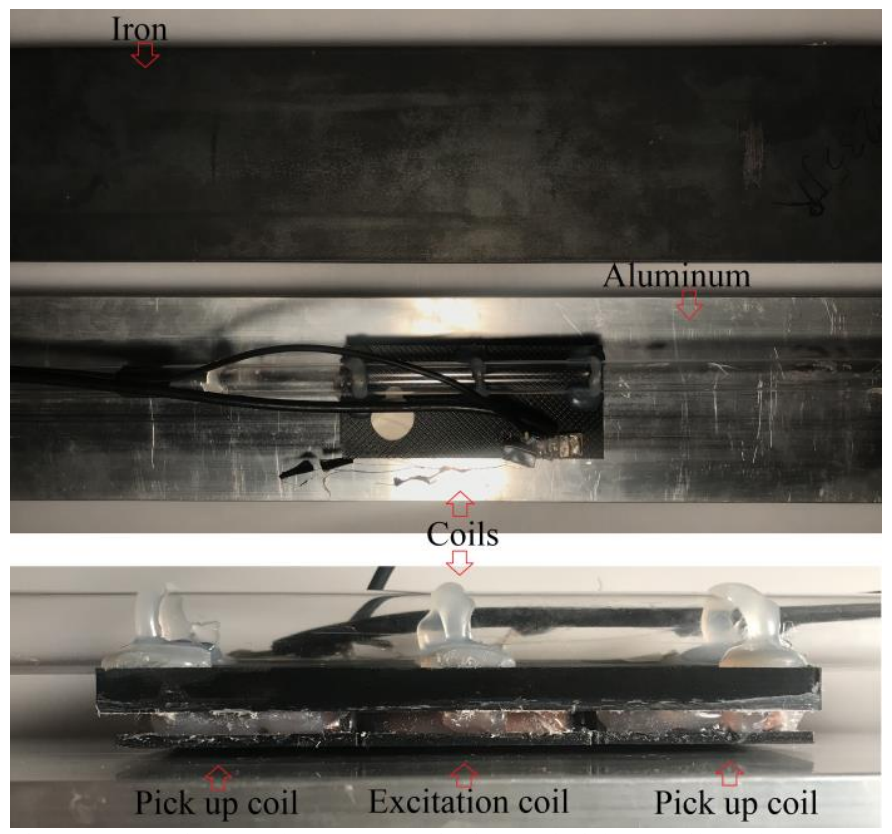

Fig. 16. Experiments elements - excitation and pick-up coils and aluminum plates (10 $\mathrm{mm}$ in thickness) and iron plates (5 $\mathrm{mm}$ in thickness)

In Table VII and Table VIII, 'air' means that there is no conductive moving part, 'iron' means that the iron moving part is located in the gap, and $g$ is the distance of the coils.

\section{TABLE VII}

COMPARISON BETWEEN THE ANALYTICAL AND 3D FEM -INDUCED VOLTAGE OF ONE OF THE PICK-UP COILS (RMS VALUE)

\begin{tabular}{ccc}
\hline \hline & Iron $(g=2 \mathrm{~mm})$ & Air \\
Analytical / Exp. & Analytical / Exp. \\
\hline$f=100 \mathrm{~Hz}$ & $3.320 / 3.488 \mathrm{mV}$ & $2.192 / 2.253 \mathrm{mV}$ \\
\hline \hline
\end{tabular}


PREPRINT - submitted verion of paper

M. Mirzaei, J. Vyhnanek, A. Chirtsov, V. Grim, P. Ripka: Design and Modeling of a Linear Speed Sensor with a Flat Type Structure and Air Coils, JMMM Vol. 495 (2020) article \#165834,pp 1-10, https://doi.org/10.1016/j.jmmm.2019.165834

\begin{tabular}{ccc}
\multicolumn{2}{c}{ COMPARISON BETWEEN ANALYTICAL AND 3D FEM - SELF INDUCTANCES } \\
\hline \hline$g=100 \mathrm{~Hz}$ & $\begin{array}{c}\text { Iron } \\
\text { Analytical / Exp. }\end{array}$ & $\begin{array}{c}\text { Air } \\
\text { Analytical / Exp. }\end{array}$ \\
\hline$g=-$ & - & $583.3 / 613.0 \mu \mathrm{H}$ \\
$g=1.0 \mathrm{~mm}$ & $820.8 / 843.0 \mu \mathrm{H}$ & - \\
$g=2.0 \mathrm{~mm}$ & $771.6 / 785.0 \mu \mathrm{H}$ & - \\
$g=6.0 \mathrm{~mm}$ & $673.0 / 698.0 \mu \mathrm{H}$ & - \\
$\mathrm{g}=7.0 \mathrm{~mm}$ & $659.8 / 682.0 \mu \mathrm{H}$ & - \\
\hline \hline
\end{tabular}

Equations (15) and (16) are used for analytical calculations of transient differential voltages at variable speeds. Acceleration effects (the second term in (15)) are neglected in (16).

$U_{d}=\frac{d\left(\left(L_{\mathrm{M}, r}-L_{\mathrm{M}, l}\right) \cdot I_{\mathrm{s}}\right)}{d t}=$
$\frac{\partial\left(\left(L_{\mathrm{M}, r}-L_{\mathrm{M}, l}\right) \cdot I \cdot \sin (\omega t)\right)}{\partial t}+\frac{\partial\left(\left(L_{\mathrm{M}, r}-L_{\mathrm{M}, l}\right) \cdot I_{\mathrm{s}}\right)}{\partial V} \cdot \frac{\partial V}{\partial t}$

$U_{d} \approx \frac{\partial\left(\left(L_{\mathrm{M}, r}-L_{\mathrm{M}, l}\right) \cdot I \cdot \sin (\omega t)\right)}{\partial t}=$

$\omega \cdot\left(L_{\mathrm{M}, r}-L_{\mathrm{M}, l}\right) \cdot I \cdot \cos (\omega t)=K \cdot V \cdot \cos (\omega t)$

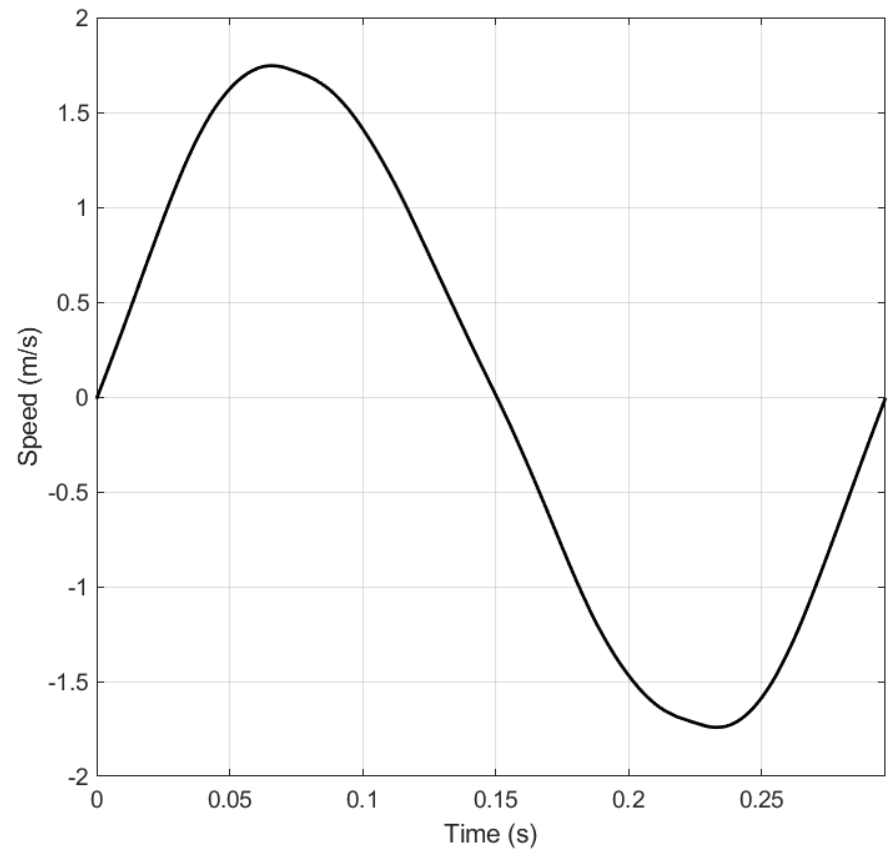

Fig. 17. Applied experimental speed versus time for an aluminum moving part

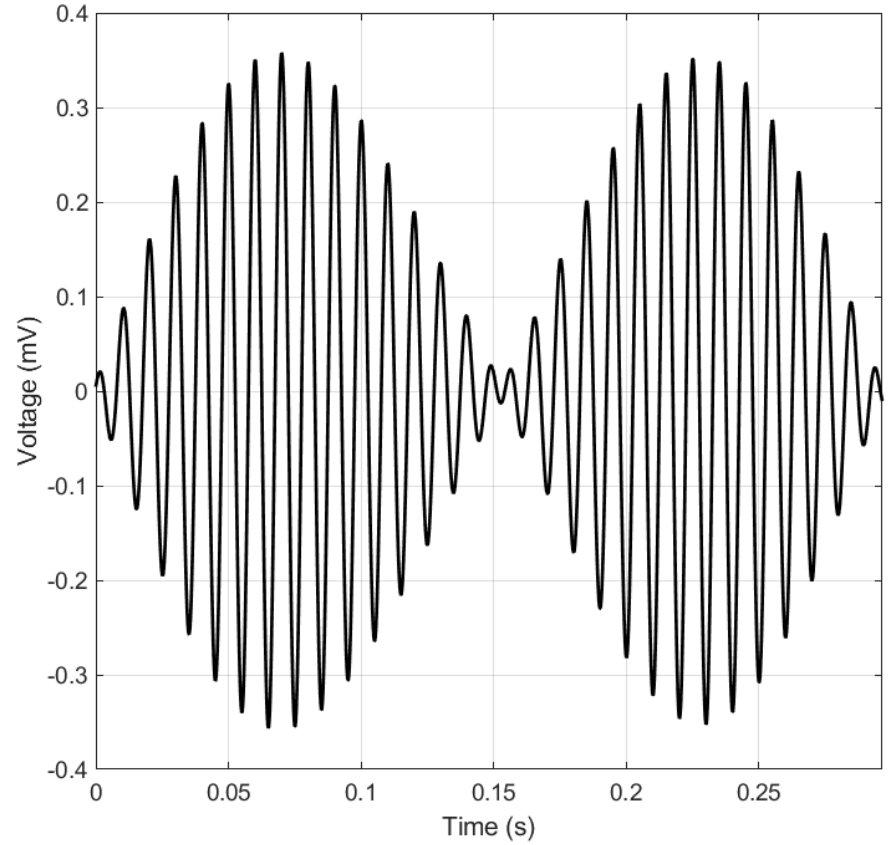

Fig. 18. Experimental differential voltage versus time for an aluminum moving part $-100 \mathrm{~Hz}$

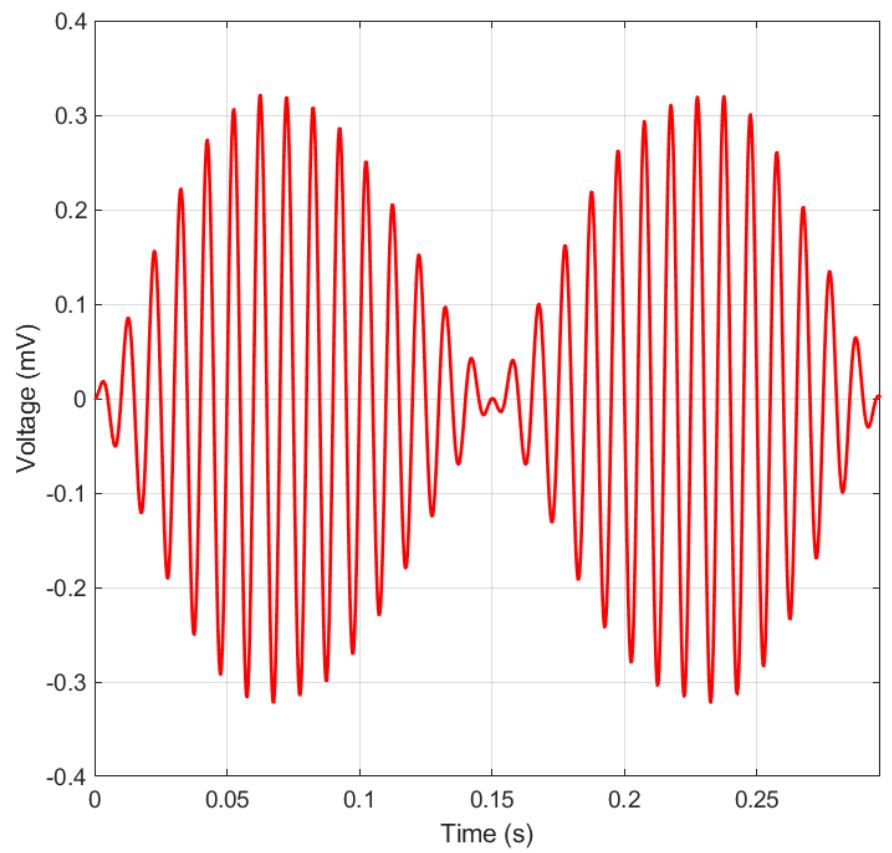

Fig. 19. Analytically calculated differential voltage versus time for an iron moving part $-100 \mathrm{~Hz}$

The analytically calculated results and the experimental values for differential voltages versus time at various speeds (Fig. 17 and Fig. 20) are shown in Fig. 18 - Fig. 19 and Fig. 21 - Fig. 22. The relative instantaneous positions of coils and moving parts are measured by a Senpos MRTM500 type potentiometric linear position sensor with a measurement range of $500 \mathrm{~mm}$ and linearity error of $0.05 \%$. The relative speed is calculated numerically using differentiation of relative positions versus time. The experimental differential voltage results at different speeds are saved by a digital 
oscilloscope.

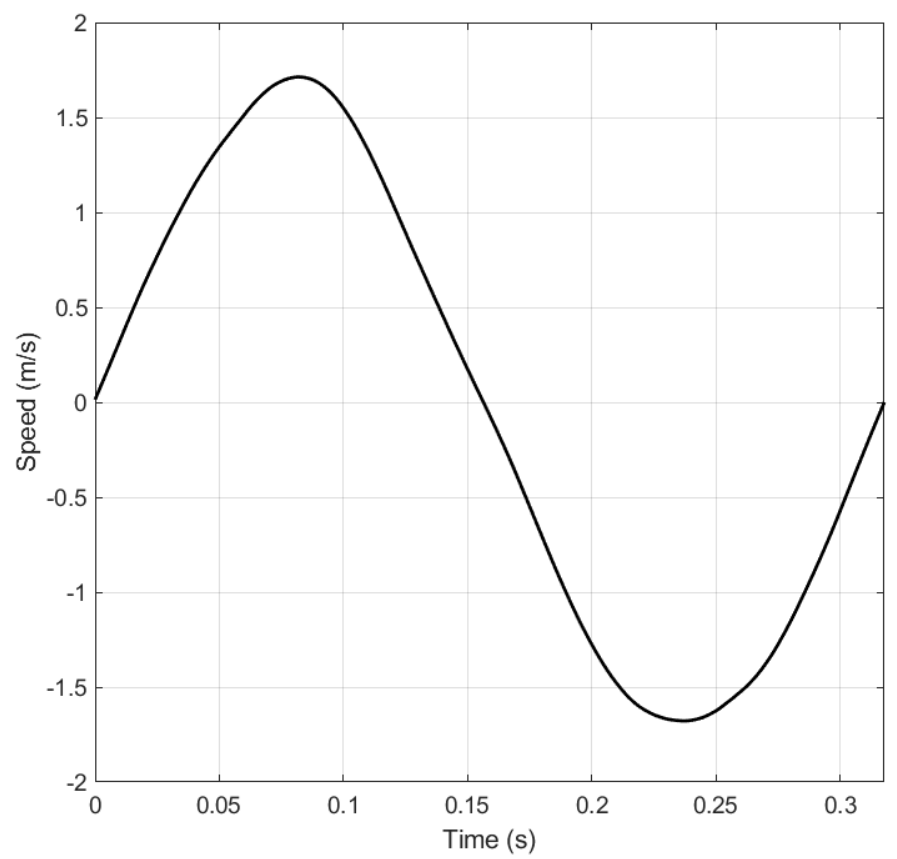

Fig. 20. Applied experimental speed versus time for an iron moving part

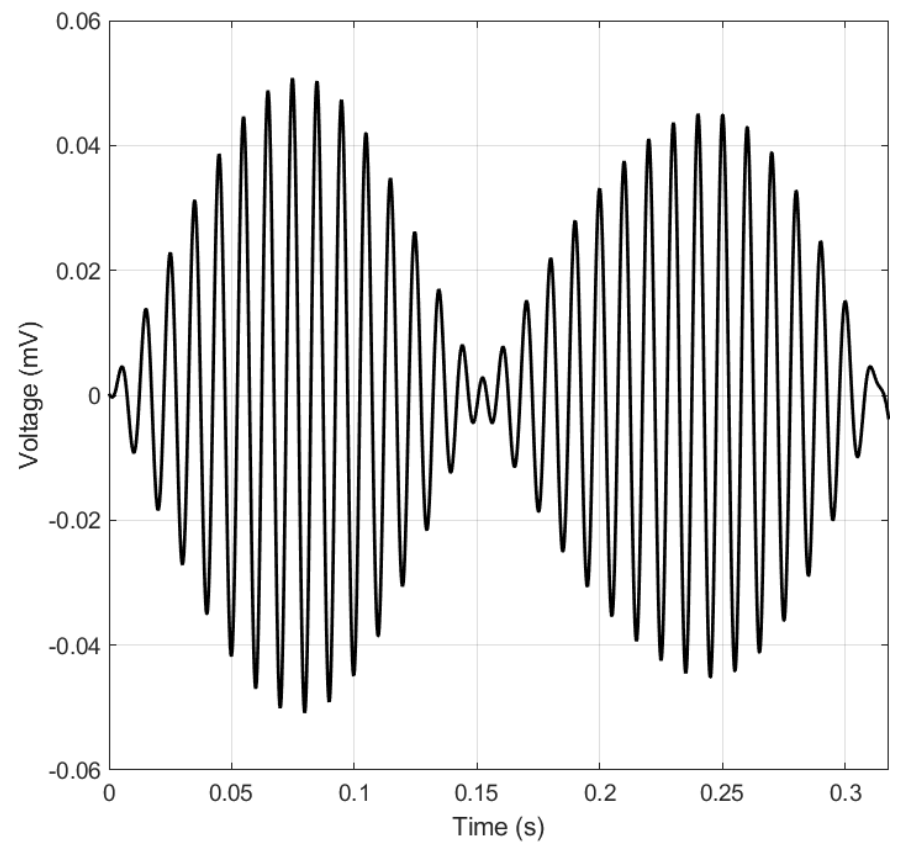

Fig. 21. Experimental differential voltage versus time for an iron moving part $-100 \mathrm{~Hz}$

The analytical induced voltages coincide well with the experimental results, showing the accuracy of the proposed analytical method. The main sources of differences between the experimental calculations and the analytical calculations may be the tolerances of the elements in the experimental set up, for example, the gap between the coils and the moving parts and the relative magnetic permeability for the iron moving part (Fig. 22). The direction (sign) of the speed could not be calculated from the amplitude of the induced voltage, but it could be obtained by calculating the phase angle relative to the excitation current. The speed values could be calculated by the voltage peaks or by the voltage RMS, or the rectified DC value in each half period can be used

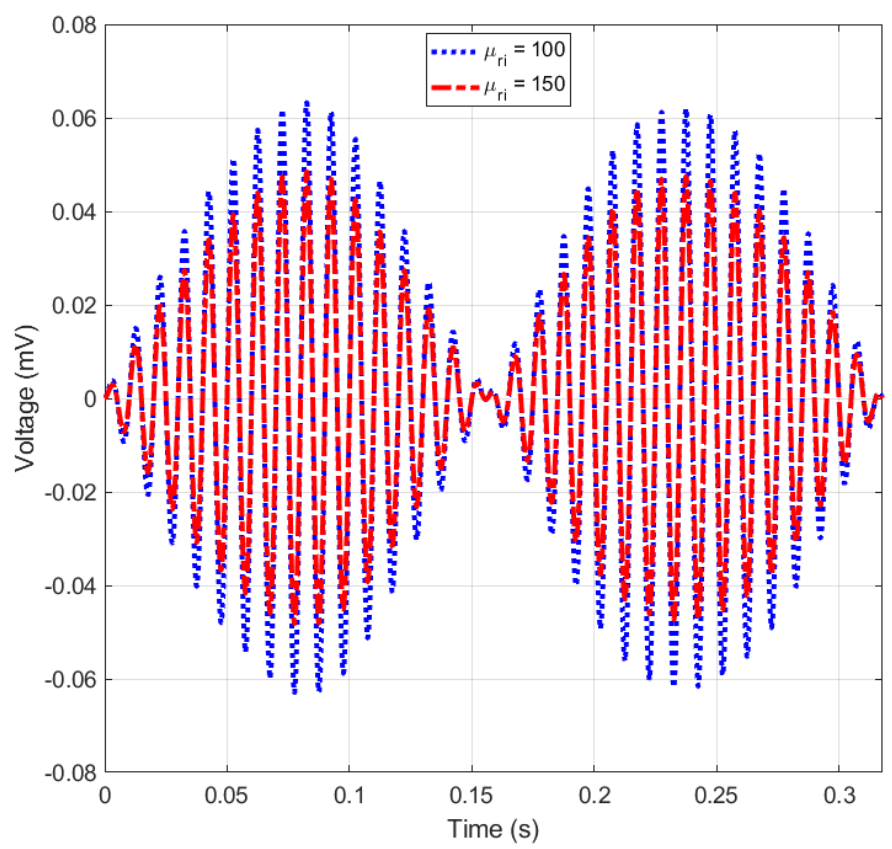

Fig. 22. Analytically calculated differential voltage versus time for an iron moving part $-100 \mathrm{~Hz}$

\section{CONCLUSION}

The performance and the design of a flat type eddy current speed sensor with air coils has been analyzed. Analytical models and 3D FEM calculations have been presented. The use of a fast and precise 3D analytical method is essential for the fast design and optimization of an air coil eddy current speed sensor. The linearity of the proposed speed sensor is excellent, despite its simple configuration. The calculated and measured speed range has been considered up to $2 \mathrm{~m} / \mathrm{s}$, but it can be extended for higher translational speed. The proposed eddy current speed sensor could be used for all types of linear machines, as it has a simple structure and precise performance. The air coil configuration enables the proposed eddy current speed sensor to be very compact and cost-effective.

The effects of the material of the conductive moving parts have been evaluated. They have been shown to have a very critical influence on the design and analysis of eddy current speed sensors, and they must be taken into account. The output results and the performance of an eddy current speed sensor with a ferromagnetic moving part differ greatly from the results and the performance with a non-magnetic moving part. It is critical to compensate the magnetic permeability and also the conductivity of the moving part in the design of an eddy current speed sensor. Temperature stability and the effects on the conductive moving part must also be taken into consideration for an eddy current speed sensor. The conductivity and even the magnetic permeability $f$ the moving part is affected by temperature. 
The proposed configuration is without the use of a magnetic yoke for the coils, and without magnetic shielding. Adding a magnetic yoke to the sensor configuration could increase the output and the sensitivity of the sensor, and would shield the sensor from magnetic parasitic effects. Perpendicular configurations of the pick-up coils are alternatives to the flat type configuration aimed at reducing the longitudinal length of the sensor. However, perpendicular configurations would reduce the sensitivity of the sensor, and would decrease the magnetic coupling between the excitation coil and the pick-up coils.

\section{REFERENCES}

[1] C.-T. Liu, S.-Y. Lin, Y.-Y. Yang, "Flux modeling and analysis of a linear induction motor for steel mill non-contacting conveyance system application," Journal of Magnetism and Magnetic Materials, 290-291, pp. 1359-1362, 2005

[2] C.-T. Liu, S.-Y. Lin, Y.-Y. Yang, C.-C. Hwang, "Analytical model development of an eddy-current-based non-contacting steel plate conveyance system," Journal of Magnetism and Magnetic Materials, 320, pp. 291-295, 2008

[3] Z. Zhang, C. Xi, Y. Yan, Q. Geng, T. Shi, "A hybrid analytical model for open-circuit field calculation of multilayer interior permanent magnet machines," Journal of Magnetism and Magnetic Materials, 435, pp. 136-145, 2017

[4] D. Zeng, G. Lv, and T. Zhou, "Equivalent circuits for single-sided linear induction motors With asymmetric cap secondary for linear transit," IEEE Trans. on Energy Conversion, vol. 33, no. 4, pp. 1729-1738, Dec. 2018

[5] N. Fernando, P. Arumugam, and C. Gerada, "Design of a stator for a high-speed turbo-generator with fixed permanent magnet rotor radius and volt-ampere constraints," IEEE Trans. on Energy Conversion, vol. 33, no. 3, pp. 1311-1320, Sept. 2018

[6] P. Ripka, Magnetic Sensors and Magnetometers, Artech House, Jan 1, 2001 - Technology \& Engineering

[7] X. Ge, Z. Q. Zhu, R. Ren, and J. T. Chen, "A novel variable reluctance resolver with non-overlapping tooth-coil windings," IEEE Trans. on Energy Conversion, vol. 30, no. 2, pp. 784-794, June 2015

[8] X. Ge and Z. Q. Zhu, "A novel design of rotor contour for variable reluctance resolver by injecting auxiliary air-gap permeance harmonics," IEEE Trans. on Energy Conversion, vol. 31, no. 1, pp. 345-353, March 2016

[9] N. Takehira, and A. Tanaka, "Analysis of a perpendicular-type eddycurrent speed meter," IEE Proc. A - Phys. Science, Meas. and Instr., Manag. and Educ.- Rev. , vol. 135 , no. 2, pp. 89 - 94, Feb. 1988

[10] T. Itaya, K. Ishida, A. Tanaka, N. Takehira, and T. Miki, "Eddy current distribution for a rectangular coil arranged parallel to a moving conductor slab," IET Science, Meas. \& Tech., vol. 6, no. 2, pp. 43 - 51, Mar. 2012

[11] T. Itaya, K. Ishida, A. Tanaka, and N. Takehira, "Analysis of a forkshaped rectangular coil facing moving sheet conductors," IET Science, Meas. \& Tech., vol. 3 , no. 4, pp. 279 - 285, Jul. 2009

[12] A. Tuysuz, M. Flankl, J. W. Kolar, and A. Mutze, "Eddy-current-based contactless speed sensing of conductive surfaces," IEEE 2nd Annual Southern Power Electronics Conference (SPEC), pp. 1 - 6, Dec. 2016

[13] M. Mirzaei, P. Ripka, A. Chirtsov, and J. Vyhnanek, "Eddy current linear speed sensor," IEEE Trans. Mag., vol. 55 , no. 1, pp. 1-4, Jan. 2018

[14] H.H. Woodson, and J.R. Melcher, Electromechanical dynamics, Part II, John Wiley \& Sons, Inc., 1968

[15] J.A. Shercliff, The theory of electromagnetic flow measurement, Cambridge University Press, 1962

[16] K. Yoshida, "New transfer-matrix theory of linear induction machines, taking into account longitudinal and transverse ferromagnetic end effects," IEE Proceedings B - Electric Power Applications, vol. 128 , no. 5, pp. 225-236, Sept. 1981

[17] D. Schieber, Electromagnetic Induction Phenomena, Springer-Verlag, 1986 - Science
[18] K. Davey, "Analytic analysis of single- and three-phase induct-ion motors," IEEE Trans. on Mag., vol. 34, no.5, pp. 3721- 3727, Sept. 1998

[19] S. Salon, Finite Element Analysis of Electrical Machines, Springer US, 1995 